\title{
Retraction Note: Urban groundwater quality monitoring and state-owned assets management optimization based on spatial information processing
}

\author{
Xiaomeng Liu ${ }^{1}$
}

Published online: 6 December 2021

(c) Saudi Society for Geosciences 2021

Retraction Note: Arabian Journal of Geosciences (2021) 14: 1467

https://doi.org/10.1007/s12517-021-07761-5

The Editor-in-Chief and the Publisher have retracted this article because the content of this article is nonsensical. The peer review process was not carried out in accordance with the Publisher's peer review policy. The author has not responded to correspondence regarding this retraction.

The original article can be found online at https://doi.org/10.1007/ s12517-021-07761-5.

Xiaomeng Liu

1xm19911211@163.com

1 School of Economics and Management, Hefei University, Hefei 230601, Anhui, China 